\title{
UMA ABORDAGEM PARA O ESTUDO DO PLANEJAMENTO, PROGRAMAÇÃO E CONTROLE DA PRODUÇÃO - (PPCP).
}

Gabriel Toledo Cardoso ${ }^{1}$, João Francisco Saraiva Puglisi ${ }^{1}$, Mateus Seribeli Neto ${ }^{1}$, Porfirio Henrique de Sá Filho ${ }^{1}$, Andréia de Menezes Olivo ${ }^{2}$.

Universidade do Oeste Paulista - UNOESTE, Curso de Engenharia de Produção, Presidente Prudente, SP.Email: mateus.seribeli@gmail.com

\section{RESUMO}

O meio empresarial encontra-se em grande disputa competitiva, consequentemente as organizações precisam estar em constante desenvolvimento. E o PPCP é a função administrativa que as empresas utilizam com o propósito de aplicar efetivamente os seus recursos disponíveis, para que essa possa conquistar espaço continuamente. Em vista disso o PPCP indica quais são as melhores medidas a serem tomadas, cumprindo os prazos estabelecidos, atendendo a previsão de demanda e minimizando os desvios por meio do controle da produção. O objetivo desse estudo é realizar um levantamento a respeito da conceituação do PPCP, a partir de suas etapas, sendo-as respectivamente o Planejamento, Programação e Controle da Produção, expondo a sua importância e características fundamentais dentro de uma empresa produtora de bens ou serviços. O trabalho utilizou-se da abordagem qualitativa, baseada em uma pesquisa descritiva e analítica, com levantamento bibliográfico pautado em livros, artigos e trabalhos acadêmicos científicos.

Palavras-chave: Planejamento, Programação, Controle, Produção, Administração.

\section{AN APROACH TO THE STUDY OF THE PLANNING, PROGRAMING AND PRODUCTION CONTROL - (PPCP)}

\begin{abstract}
The business world is in a big competitive dispute, consequently, the organizations need to be developing constantly. The PPCP is an administrative function used by companies with a purpose to apply effectively their available resources. In order to conquest its space continuously. Based on that, O PPCP indicates which are the better position to be taken, meeting the established deadlines, attending to demand forecast and minimizing the deviations by production control. Its aimed to undertake a survey from the concepts of PPCP, from that stages, that are, respectively, planning, programing and control of production, exposing its importance and fundamental specificities into a productive company of goods or services. The research chose the qualitative approach, based on a descriptive and analytical research with literature guided in books, articles and academic and scientific papers.
\end{abstract}

Keywords: Planning, Programming, Control, Production, Management. 


\section{INTRODUÇÃO}

A partir da globalização iniciada na década de noventa as organizações brasileiras passaram a estar sujeitas à concorrência mundial, isto resultou na obrigatoriedade destas em atender as expectativas e necessidades dos clientes para se manterem em um ambiente competitivo. Dessa forma, as organizações devem adequar seus sistemas para o aperfeiçoamento da produtividade, gerando sistemas flexíveis e sustentáveis, com celeridade de projeto e elaboração de novos produtos, além de fazer com que os estoques e lead times ${ }^{1}$ sejam reduzidos ( $\mathrm{NANCl}$ et al., 2008). Planejar e controlar a produção são processos fundamentais para alcançar as exigências mencionadas, e para tal, as organizações contam com o que se denomina Planejamento, Programação e Controle da Produção (PPCP).

O PPCP é o departamento da organização que determina o que, quando, quanto, onde e como vai ser produzido (PASQUINI, 2016). Conforme Graziani (2012) é uma área de decisão da empresa determinada a planejar e controlar os recursos destinados ao processo produtivo, almejando satisfazer os pedidos dos clientes. O autor ainda ressalta que o PPCP é a função da gestão que une a produção às demais funções da empresa por meio da informação.

O Planejamento, Programação e Controle da Produção opera dentro de três níveis: nível estratégico, nível tático e nível operacional. No nível estratégico, acontece a elaboração do Plano de Produção, sendo esse a longo prazo. No nível tático, o Plano de Produção é fragmentado em um Plano-mestre de Produção, no qual os bens e serviços que serão realizados são especificados. E no nível operacional, ocorre à programação e acompanhamento da aplicação do plano mestre. (TUBINO, 2007)

Este estudo tem como objetivo propiciar conhecimento teórico, bem como expor as suas respectivas etapas de aplicação, com a finalidade de demonstrar a sua importância dentro de uma empresa produtora de bens e serviços, uma vez que ele é peça fundamental para se obter sucesso. Quanto à metodologia usada nesta pesquisa optou-se pela abordagem qualitativa, baseada em uma pesquisa descritiva e analítica, pautada em livros, artigos e trabalhos acadêmicos científicos.

\section{PLANEJAMENTO, PROGRAMAÇÃO E CONTROLE DA PRODUÇÃO - (PPCP) Planejamento da Produção}

Planejamento constitui na formalização do que se pretende alcançar no futuro. Um plano não assegura que um evento vá realmente acontecer, é uma manifestação de intenção de que aconteça. Apesar dos planos serem pautados em expectativas, no momento de sua implementação nem tudo ocorre como o planejado. (SLACK; CHAMBERS; JOHNSTON, 2009)

De acordo com Chiavenato (2008) o planejamento previne as empresas de desperdícios, atrasos, perdas de tempo e garante um sucesso futuro. O planejamento procura reunir a mão de obra, as matérias-primas e as máquinas em sintonia com a capacidade de produção e a previsão de vendas.

A importância do planejamento apresentada por Chiavenato (2008) consiste que com a sua ausência a organização perde-se no caos. Por conseguinte, originando-se da definição dos objetivos a serem atingidos, estabelece a priori o que se deve fazer, quando fazer, quem deve fazê-lo e de que modo. E esse é feito na base de um conjunto de planos. Desse modo, Tubino (2007) aborda que estes planos são elaborados por meio de um Planejamento Estratégico e de um Planejamento Mestre de Produção.

O Planejamento estratégico é o processo administrativo que concede suporte metodológico para determinar a melhor diretriz a ser seguida pela organização, alvejando a um desejado nível de relação com os fatores externos e trabalhando de modo inovador e

\footnotetext{
${ }^{1}$ Tempo de espera
} 
diferenciado. Um planejamento estratégico incorpora a empresa por completo, contudo de modo isolado se torna insuficiente, pois age a longo prazo. (OLIVEIRA, 2015)

Nanci et al. (2008) acrescenta que por não se tratar de um planejamento detalhado, o planejamento estratégico, torna-se impossível de mensurar com precisão todos os recursos empresariais que serão necessários para atender os objetivos estratégicos. Outrora não há a necessidade de decidir isto com muita antecedência, e mesmo que isso fosse feito, resultaria em um volume de informações e uma complexidade de planejamento inviável.

Logo o planejamento-mestre de produção surge para desmembrar os planos produtivos estratégicos de longo prazo em planos de produção para médio prazo, no intuito de guiar as etapas de programação e realização das atividades operacionais da empresa. (TUBINO, 2007)

Perante do que foi abordado percebe-se que o planejamento da produção tem como objetivo, dentro de uma organização empresarial, prevenir prejuízos através da busca pelo melhor arranjo de seus recursos empresariais, para que as decisões futuras não sejam tomadas ao acaso, entretanto, há variáveis imprevisíveis que podem interferir neste planejamento. Tendo em vista que para um planejamento de produção eficiente deve-se seguir corretamente as etapas de seu processo baseado nos recursos disponíveis, futuros, na filosofia e política da empresa englobandoa como um todo.

\section{Programação da Produção}

Depois que o plano de produção providenciou os recursos necessários e o planejamento mestre da produção resultou um plano mestre realizável, o próximo passo será programar a produção (TUBINO, 2007). Essa é responsável por desmembrar o plano de produção em ordens de aquisição e de manufaturação, que deverão ser cumpridas pelos departamentos da corporação que estão diretamente ou indiretamente conectados ao processo produtivo, sendo estes: produção, almoxarifado, compras, deposito, controle de qualidade, custo, contabilidade, pessoal etc. (CHIAVENATO, 2008)

Mesquita et al. (2008) destaca que programar a produção significa decidir quando, onde ou por quem cada tarefa deverá ser feita, para que as entregas aconteçam no tempo determinado e que todas as tarefas sejam realizadas no menor espaço de tempo, de modo a diminuir os estoques em processo e a ociosidade dos recursos. Dando continuidade à sua abordagem o autor reitera que a programação da produção é uma função operacional, isto é, de chão de fábrica.

Conforme Chiavenato (2008) programar a produção é criar uma agenda de compromissos para as diversas unidades produtivas compreendidas no processo. Para o autor a programação passa a ser a área de interação entre planejamento, execução e controle.

Moreira (2014) destaca que a programação da produção é importante porque busca minimizar os estoques e os custos operacionais, fazendo com que as máquinas e as pessoas operem com os níveis desejados de produtividade, assim como melhorar o nível de atendimento ao cliente. Para Tubino (2007) também competirá à programação minimizar lead times. Slack, Chambers e Johnston (2009) evidenciam que a programação é uma das atividades mais difíceis no gerenciamento da produção, pois os programadores têm que lidar com diferentes tipos de recursos, as máquinas apresentam diferentes capacidades e o pessoal possui diferentes habilidades.

A programação da produção é efetuada em quatro fases: aprazamento, roteiro, emissão de ordens e liberação da produção. O aprazamento consiste no encargo de prazos e na determinação de datas ou horários. Já o roteiro é a fixação da melhor sequência ou fluxo para satisfazer ao plano-mestre de produção. Posteriormente, a emissão de ordens representa um grupo de informações e coordenação da programação de produção. Por fim a liberação da produção consiste na autorização para que todos os recursos sejam empregados e coordenados para o cumprimento das ordens. (CHIAVENATO, 2008) 
Slack, Chambers e Johnston (2009) diferenciam a programação da produção em programação para frente e programação para trás. A programação para frente resume no começo da operação imediatamente a sua chegada. Já na programação para trás o trabalho é iniciado no último momento possível, mas sem que aconteçam atrasos.

Os autores ainda destacam que conhecer o conceito de programação empurrada e puxada é importante, porque elas resultam diferentes impactos sobre a acumulação de estoques. Os sistemas puxados apresentam menos tendência em resultar criação de estoques e por esta razão são beneficiados pelas operações Just in time ${ }^{2}$. Nos sistemas empurrados, os materiais são movidos para o próximo estágio logo que são produzidos, desse modo, se algum atraso acontece o resultado será a acumulação de estoques. Nos sistemas puxados, as peças são movidas para o estágio seguinte somente quando ele as requer, por esta razão os estoques não são acumulados tão facilmente como nos sistemas empurrados.

Em face do que foi apresentado, considera-se que a programação pode ser definida como um cronograma, para a realização das operações da produção conforme o planejado, com foco na redução dos estoques e no acondicionamento dos recursos em atividade. Observa-se também que a programação interage com variáveis que são significativamente difíceis de associar. Diante disso, a programação é dividida de modo a combinar tais variáveis da melhor forma possível, a fim de atingir os seus objetivos.

\section{Controle da Produção}

Para Chiavenato (2008) o controle é o responsável por mensurar e reparar o desempenho para garantir que os objetivos da empresa sejam alcançados. Sua função é analisar se tudo esta saindo como foi planejado, identificando possíveis falhas e indicando quais são as medidas corretivas. Após este procedimento, o controle indica como evitá-las futuramente, prevenindo para que essas não voltem a acontecer.

Ainda segundo o autor, o controle constitui a última fase do PPCP. Dentre as suas finalidades, destaca-se que o controle é utilizado para avaliar e monitorar constantemente as atividades produtivas de uma organização, realizar uma comparação entre o que foi planejado e o que foi realizado, indicar falhas ou desvios, produzir relatórios para a direção da empresa e comunicar outras seções sobre o prosseguimento das atividades produtivas.

Também foi levantado por Costa et al. (2008) que durante a etapa de controle ocorrem as comparações diárias entre os resultados gerados através das produções de bens e/ou serviços e as demandas da programação, com objetivo de detectar desvios através da identificação das causas desses problemas e cobrar dos responsáveis suas devidas correções. O autor ainda reitera que diagnosticar um resultado indesejável é sempre um grande inconveniente e que para um bom gerenciamento é necessário identificar os problemas e então aprender a resolvê-los, utilizando-se de um controle de processo que se resume em três ações fundamentais: estabelecimento da diretriz de controle, manutenção do nível de controle e melhoria do nível de controle.

Controlar a produção significa criar um elo com a programação a fim de garantir que as ordens de produção serão realizadas de forma e data certa. Para que isso aconteça é necessário possuir um sistema de informação que descreva frequentemente o estado atual de cada ordem de produção, os materiais em processo acumulados nos diversos centros, as quantidades produzidas de cada produto e como está sendo o uso dos equipamentos. (MOREIRA, 2014)

Costa et al. (2008) ressalta que para melhor vistoriar o sistema produtivo, o planejamento e controle da produção executa um feedback ${ }^{3}$ para os gestores, possibilitando a análise comparativa do que está sendo realizado com o planejado. Ligado ao ambiente competitivo atual,

\footnotetext{
${ }^{2}$ na hora certa

${ }^{3}$ parecer
} 
o controle da produção dedica-se desde o fluxo de materiais e matérias primas até o produto acabado, cuidando do tempo, da quantidade produzida e dos operários.

Mediante a abordagem de Tubino (2007) a eficiência das ações de acompanhamento e controle da produção é relevante porque resulta na redução das medidas corretivas, do tempo e despesas com tais atividades de correção.

Pode-se concluir que o controle é responsável pelo cumprimento dos objetivos propostos pelos planos de produção, por meio da identificação de inconformidades no processo produtivo, dessa maneira age primeiramente de forma corretiva e posteriormente propõe ações de prevenção. Nota-se a ligação entre o controle da produção e programação através de ferramentas de auxilio, realizando um comparativo do que foi ordenado para produzir perante o que realmente está sendo produzido, buscando soluções a curto prazo de modo a viabilizar o alcance das metas pré-estabelecidas pela corporação.

\section{CONSIDERAÇÕES FINAIS}

O presente trabalho almejou proporcionar conteúdo cientifico abordando o conceito e a importância do PPCP no que diz respeito a sua aplicabilidade como função administrativa apresentando-o por via de suas respectivas etapas.

Em relação ao conceito foi abordado que o Planejamento, Programação e Controle da Produção está determinado a relacionar os seus recursos destinados ao processo produtivo de modo a atingir os seus objetivos de desempenho, para que conquiste a satisfação de seus clientes. Por isso ele é a função administrativa que conecta a produção aos demais departamentos da corporação por meio da informação.

Observa-se com base na abordagem realizada, que o PPCP é composto inicialmente pelo planejamento, esse que coloca em pauta as ambições da empresa considerando seus limites e possibilidades, prevenindo-a de prejuízos através da otimização de suas operações e emprego de seus recursos. Não menos importante a programação transforma o planejado em uma agenda de compromissos, destinada aos departamentos ligados ao processo produtivo a fim de executar os planos. Por último e de suma relevância o controle da produção é a etapa responsável por monitorar as operações para verificar se estão de acordo com o planejado e programado, corrigindo-as sempre que necessário.

Através do levantamento realizado pode-se notar a apresentação das principais características, funções e benefícios do PPCP nas organizações. O estudo deixa evidente como a utilização do Planejamento, Programação e Controle da Produção é fator primordial para a agregação de diversos valores para a empresa, de modo a se destacar no âmbito competitivo.

\section{REFERÊNCIAS}

CHIAVENATO, I. Planejamento e Controle da Produção. 2. ed. São Paulo: Manole, 2008.

COSTA, H. G. et al. Sistemas de controle da produção. In: LUSTOSA, Leonardo (Org.). Planejamento e Controle da Produção. 4ํ reimpressão. Rio de Janeiro: Elsevier, 2008.

GRAZIANI, Á. P. Planejamento, programação e controle da produção: livro didático. Palhoça: UnisulVirtual, 2012.

MESQUITA, M. et al. Programação detalhada da produção. In: LUSTOSA, Leonardo (Org.). Planejamento e Controle da Produção. 4ㅇr reimpressão. Rio de Janeiro: Elsevier, 2008.

MOREIRA, D. A. Administração da Produção e operações. 2. ed. São Paulo: Cengage Learning, 2014.

NANCI, L. C. et al. O PPCP no contexto estratégico. In: LUSTOSA, Leonardo (Org.). Planejamento e Controle da Produção. 4ㅇ reimpressão. Rio de Janeiro: Elsevier, 2008. 
OLIVEIRA, D. P. R. Planejamento Estratégico. 33. ed. São Paulo: Atlas, 2015.

PASQUINI, N. C. Planejamento e Controle da Produção: estudo da arte. R.TecFatecAM, Americana, v. 3, n. 2, p. 81-97, set.2015/mar.2016

SLACK, N.; CHAMBERS, S.; JOHNSTON, R. Administração da Produção. 3. ed. São Paulo: Atlas, 2009.

TUBINO, D. F. Planejamento e Controle da Produção: teoria e prática. São Paulo: Atlas, 2007. 